\title{
FINANCIAMENTO DA EDUCAÇÃO E O GASTO POR ALUNO: ENTRE AVANÇOS E RECUOS
}

\author{
JORGE MARCOS RAMOS \\ SÉRGIO MARCUS NOGUEIRA TAVARES
}

\begin{abstract}
RESUMO
Visando promover alteração do papel do Estado, em 1988 foi promulgada a Constituição chamada Cidadã tendo como marca principal a ampliação dos direitos sociais em especial o direito à educação pública, gratuita e de qualidade. O objetivo dessa pesquisa foi apresentar o percurso histórico em relação ao financiamento da educação no Brasil como uma vinculação de percentuais mínimos dos recursos tributários e os riscos para o país em abordar o assunto referente ao investimento financeiro na educação observando somente o percentual do PIB sem levar em conta outras variáveis, em especialo número de pessoas em idade escolar. Foi realizada revisão de literatura, visando discorrer sobre o financiamento público da educação. Foram considerados artigos, dissertações, teses, livros e documentos legais publicados nos últimos dez anos (2011-2020), escritos em português, inglês e espanhol. Esperar somente que a dinâmica natural de redução da população em idade educacional como recurso para o aumento do investimento por aluno é um risco, pois nessa perspectiva
\end{abstract}

* Doutorando em Educação no PPGE - UMESP.

** Doutor em Educação pela Universidade Federal de São Carlos - UFSCar. Professor do Programa de Pós-graduação Stricto Senso em Educação da Universidade Metodista de São Paulo - UMESP. Coordenador do Programa de Pós-graduação Stricto Senso em Educação da Universidade Metodista de São Paulo - UMESP

Cadernos de Educação, v.20, n. 40, jan.-jun. 2021 
muitos serão àqueles que não terão acesso a uma educação de qualidade e ficarão, uma vez mais, excluídos do desenvolvimento para a cidadania.

Palavras-chave: Educação pública, ensino gratuito, financiamento, PIB

\title{
EDUCATION FINANCING AND SPENDING PER STUDENT: ADVANCES AND RETREATS
}

\begin{abstract}
Aiming to promote a change in the role of the State, in 1988 the Constitution called Citizen was promulgated, with the main feature being the expansion of social rights, especially the right to free, quality public education. The objective of this research was to present the historical path in relation to the financing of education in Brazil as a linkage of minimum percentages of tax resources and the risks for the country in addressing the issue related to financial investment in education, observing only the percentage of GDP without taking account for other variables, in particular the number of people of school age. A literature review was carried out, aiming to discuss the public financing of education. Articles, dissertations, theses, books and legal documents published in the last ten years (2011-2020), written in Portuguese, English and Spanish were considered. Just hoping that the natural dynamics of reducing the population of educational age as a resource for increasing investment per student is a risk, as in this perspective many will be those who will not have access to quality education and will be, once again, excluded from the development for citizenship.
\end{abstract}

Keywords: Public education, free education, financing, GDP

\section{INTRODUÇÃO}

Com a perspectiva de promover e reformar o papel do Estado no Brasil, em 1988 foi promulgada a atual Constituição Federal, chamada Constituição Cidadã. A principal marca dessa 
foi a ampliação dos direitos sociais que são descritos pela primeira vez em um texto constitucional brasileiro.

Nesse novo contexto o Poder Público teve as responsabilidades sociais expandidas, passando a ser responsável por políticas públicas voltadas ao seu cumprimento. Dentre esses direitos sociais, iremos nos atentar exclusivamente ao direito à educação.

Assim como as Constituições, as Leis de Diretrizes e Bases da Educação (LDB) refletem as mudanças políticas que aconteceram na sociedade no campo educacional. Tanto é verdade que o projeto da primeira LDB foi fruto do anseio popular por uma educação igualitária como direito de todos, dando origem à Lei no 4.024/61, sancionada em 20 de dezembro de 1961. A referida Lei sofreu modificações e foi objeto de reforma pela Lei $n^{\circ}$ 5.692/71 até ser substituída pela atual LDB n 9.394/96.

É possível verificar a evolução da legislação brasileira em relação à garantia do direito à educação, que na Constituição Federal de 1988 foi consagrada como direito público subjetivo. Esse direito, garantido inicialmente somente para o ensino fundamental, foi aos poucos se expandindo abrangendo todas as etapas da educação. Por meio da Emenda Constitucional $\mathrm{n}^{\circ}$ 59 de 2009, foi dado garantia ao acesso a educação para todos dos 4 aos 17 anos.

Infelizmente, o avanço constitucional não foi prontamente efetivado, sendo necessárias várias ações e políticas públicas por parte do Poder Público a fim de promover eficácia e alcance social ao referido direito.

Conforme preconiza o artigo 205 da Constituição Federal (CF) de 1988, a educação é um direito de todos e dever do Estado e da família. Dessa forma, como dever do Estado ela deve ser financiada por recursos públicos que são oriundos dos impostos cobrados da população brasileira, os quais são dependentes do desempenho econômico do País. E, como um direito da família, a educação pode ser financiada por recursos próprios por meio do pagamento das anuidades escolares nas instituições privadas, para àqueles que optarem por estudar nessas instituições. 
Em relação aos recursos públicos arrecadados por meio dos impostos junto à população brasileira e que devem ser aplicados na educação do País, a CF estabeleceu vinculações mínimas distribuídas entre os entes federativos (Governo Federal, Estadual, Distrito Federal e Municipal). Vale destacar que os investimentos públicos na educação, obedecendo somente os percentuais mínimos preconizados pela CF, têm levado à utilização de volumes de recursos financeiros que não ultrapassam o equivalente a $5 \%$ do Produto Interno Bruto (PIB).

É necessário compreender que esses investimentos relacionados a percentuais do PIB contemplam todas as etapas da educação, sendo elas: o ensino infantil, o ensino fundamental, o ensino médio e o ensino superior. No entanto, além de observar o percentual do PIB que está sendo aplicado na educação, se faz necessário analisar outras variáveis envolvidas nesse processo como, por exemplo, o valor desse PIB: ou seja, 5\% de qual valor? Ou o quantitativo de pessoas em idade educacional que irão utilizar desses recursos, pois esse valor referente ao percentual do PIB deverá contemplar todo esse quantitativo de pessoas em idade educacional.

O objetivo desta pesquisa foi apresentar o percurso histórico em relação ao financiamento da educação como uma vinculação de percentuais mínimos dos recursos tributários e os riscos para o país em delimitar o investimento financeiro na educação observando somente o percentual do PIB.

\section{METODOLOGIA}

Esta pesquisa se caracterizou como revisão de literatura, por meio de análise de conteúdo, visando discorrer sobre o financiamento público relacionado à educação.

Para a realização da busca dos documentos foi utilizada a combinação das palavras chaves: educação pública, ensino gratuito, financiamento e PIB. Esse recorte temporal se justifica tendo em vista que este é o período de vigência do II Plano 
Nacional de Educação. Esse recorte temporal se justifica tendo em vista que este é o período de vigência do II Plano Nacional de Educação.

Como critérios de inclusão, os documentos deveriam referir-se à vinculação de recursos públicos para a educação como parâmetro para a justificativa dos investimentos nessa área. E como critérios de exclusão, os documentos que não apresentaram informações relevantes para essa pesquisa.

\section{FINANCIAMENTO PÚBLICO PARA A EDUCAÇÃO}

Em diferentes momentos da história do Brasil é possível observar como foi desenvolvido o financiamento da educação pública. Segundo De Rezende Pinto (2000), no período correspondente aos anos de 1549 a 1759 o Estado delegou à Igreja, que era representada pelos jesuítas, o direito ao exercício da educação pública no país.

Com a expulsão dos jesuítas, a educação vivenciou até o fim da República Velha um período em que se buscavam fontes autônomas para o financiamento da educação como o subsídio literário, bem como a previsibilidade de recursos públicos para o seu desenvolvimento (DE REZENDE PINTO, 2000).

Contudo por intermédio da CF de 1934 foi definido como principal mecanismo de financiamento da educação, a vinculação de um percentual mínimo dos recursos oriundos dos impostos.

A CF de 1934 ficou marcada pela busca de uma vinculação constitucional de um percentual mínimo de recursos para promover o financiamento da educação pública no País. Vale destacar que essa vinculação constitucional mínima de recursos foi, e é, marcada por avanços e retrocessos, gerando instabilidade na gestão educacional, o que compromete, evidentemente, a efetivação da sua qualidade e equidade.

A referida CF apresentou, pela primeira vez, a sistematização sobre os direitos sociais e dentre eles o direito à educação. contudo mesmo considerando esse pioneirismo frente à 
explicitação da vinculação de tributos para a área da educação, se faz necessário destacar alguns momentos anteriores e que contribuíram para o seu ordenamento naquele momento (DE REZENDE PINTO, 2000). Diferentes vozes começaram a se fazer ouvir, no período anterior à Carta de 1934, responsabilizando o Estado frente ao desenvolvimento da educação. Essas vozes passaram a questionar uma maior inter-relação entre o direito a educação e o dever do Estado.

Segundo Cury (2001) esses questionamentos, que partiram de diferentes setores da sociedade, pouco alteraram a situação da educação nacional naquele momento. Contudo, proporcionaram muita discussão, o que auxiliou na compreensão dos movimentos e iniciativas posteriores referentes ao papel do Estado em relação à educação.

O direito preconizado pela CF de 1934 não se fez incidir sobre o Estado para o cumprimento dessa norma, sendo que o princípio da obrigatoriedade estava relacionado somente à frequência do público matriculado e não ao oferecimento de vagas por parte do Estado, que deveria garantir esse direito (ROCHA, 2001).

Por meio dos debates e das reivindicações populares de que o Estado não poderia mais se ausentar em relação ao financiamento da educação. A CF de 1934 apresentou, enfim, pela primeira vez, a vinculação de recursos públicos para a área da educação em seu Artigo 156:

A União e os Municípios aplicarão nunca menos de dez por cento, e os Estados e o Distrito Federal nunca menos de vinte por cento, da renda resultante dos impostos na manutenção e no desenvolvimento dos sistemas educativos (BRASIL, 1934).

É importante destacar que durante a vigência da CF de 1934 a aplicação de recursos públicos na área da educação se 
manteve em níveis irrelevantes, todavia, o princípio da vinculação foi significativo para a sua manutenção nos demais documentos constitucionais, estando presente na atual CF de 1988.

Outro aspecto relacionado à CF de 1934 que merece destaque foi a autorização referente à aplicação de recursos públicos no ensino privado, pois, conforme Rocha (2001), no momento da Constituinte, as escolas privadas apresentavam resistência a qualquer intromissão do Estado, pensando em tudo menos em solicitar recursos para esse. No entanto, em momentos subsequentes, o sistema de bolsas de ensino para alunos carentes e empréstimos subsidiados pelo Estado fizeram com que essas instituições deixassem de se preocupar com a possível interferência e passassem a disputar a verba pública.

Com a decretação da ditadura do Estado Novo em 1937, foi revogada a vinculação constitucional dos recursos financeiros para a educação, somente em 1946 essa vinculação retornou ao texto constitucional preconizada pela CF de 1934. Nesse momento foram mantidos os mesmos índices apresentados pela União, Estados e Distrito Federal, contudo conforme o artigo 169, a participação dos Municípios foi alterada para nunca menos que $20 \%$ da renda provenientes dos tributos que deveriam ser utilizadas para a manutenção e desenvolvimento do setor educacional (BRASIL, 1946).

A LDB n ${ }^{\circ}$ 4.024/61 ampliou a vinculação de recursos da União para $12 \%$, porém, a referida vinculação foi anulada pela Constituição Federal de 1967, que ocorreu após a implantação da ditadura militar de 1964. Com isso, o setor da educação apresentou um período de retração em relação a novas conquistas.

Mesmo com diferentes tentativas para a manutenção da vinculação do financiamento constitucional para o setor educacional, em 1967 esse pressuposto foi revogado sob a alegação de que o mesmo era incompatível com o sistema orçamentário apresentado pela nova Constituição, em especial na parte relacionada à proibição de qualquer vinculação entre receita de impostos e 
despesas (HORTA, 2001). A CF de 1967 foi totalmente reescrita obedecendo aos princípios autoritários da época, contudo foi mantido o acesso à educação como um direito de todos e um dever do Estado (COSTA, 2002).

Nesse período, durante a vigência do Ato Institucional 05 (AI-5) o Governo Central instituiu para si, como também para os Estados, o direito da não vinculação de seus respectivos recursos para a educação, contudo o referido Ato em seu art. 15, parágrafo $3^{\circ} \mathrm{f}$, manteve as vinculações Municipais nos percentuais de $20 \%$ das suas arrecadações por meio dos impostos, em especial para o ensino primário.

Com a implementação da LDB n ${ }^{0} 5.692 / 71$ em relação ao ensino de $1^{\circ}$ e $2^{\circ}$ graus, manteve-se a determinação referente à vinculação de pelo menos $20 \%$ dos tributos Municipais para o ensino de $1^{\circ}$ grau.

O referido período foi marcado por enormes dificuldades na área educacional, pois era observado um aumento significativo do número de matrículas em decorrência da migração do campo para a cidade, como consequência das alterações do mercado de trabalho, bem como a Lei $n^{\circ} 5.692 / 71$, que passou a obrigar a ampliação da escolaridade de quatro para oito anos. Essas novas situações assinalavam certa controvérsia em relação à redução dos aportes financeiros destinados à educação, em especial por parte da União, e aumento do número de alunos para serem atendidos pelas escolas (DE REZENDE PINTO, 2000).

O recorte temporal supracitado evidencia que a vinculação de recursos públicos para o financiamento da educação se fez de maneira intercalada nas diferentes Constituições, tendo sido subtraída dos documentos durante os períodos ditatoriais como observado no Estado Novo em 1937, bem como em 1967, período este que sucedeu a intervenção militar de 1964. O importante é que o princípio da vinculação prevaleceu.

A vinculação de recursos públicos para a área da educação, levando em conta os períodos de descontinuidade, assumiu 
valores percentuais crescentes sendo que essa maior vinculação foi observada na promulgação da atual CF de 1988.

Dessa forma, a CF de 1988 preconizou que a União deveria aplicar pelo menos 18\% dos recursos oriundos dos impostos por ela arrecadados. Os Estados e o Distrito Federal deveriam aplicar pelo menos $25 \%$ do volume dos impostos por eles arrecadados na educação e os Municípios deveriam aplicar pelo menos $25 \%$ do volume de impostos por eles arrecadados.

Vale pontuar que a CF de 1988, em seu art. 213, determinou que os recursos públicos deveriam ser destinados às escolas públicas. Contudo, esse mesmo artigo permite que esses recursos possam ser direcionados para as escolas comunitárias, confessionais ou filantrópicas para a aquisição de bolsas de estudos para as etapas do ensino fundamental e médio permitindo com isso a transferência de recursos destinados para a educação pública para a iniciativa privada.

\section{VINCULAÇÃO DE PERCENTUAL DO PIB NA EDUCAÇÃO}

Em relação ao investimento público na educação a $\mathrm{CF}$ determinou um percentual mínimo para vinculação na área da educação. Na Conferência Nacional de Educação (CONAE) de 2010 foi pleiteada uma porcentagem de 10\%, contudo o referido percentual não foi aprovado, ficando como meta a utilização de 7\% do Produto Interno Bruto (PIB) com a perspectiva de alcançar os 10\% nos próximos Planos Nacionais de Educação (PNE).

Também coube a CF de 1988 determinar a elaboração do PNE e nesse documento foi instituído como fonte de investimento na educação um percentual do Produto Interno Bruto (PIB). Em relação ao I PNE, que abrangeu o período de 2001 a 2010, esse foi aprovado com diversos vetos presidenciais em especial os itens que promoviam a ampliação do aporte de recursos financeiros para a educação. Um dos pontos que foi vetado dizia respeito à elevação gradual da porcentagem do PIB para 
que pudesse atingir o patamar de 7\%, com isso o I PNE não estabeleceu uma meta para a elevação do PIB como mecanismo de financiamento da educação (AMARAL, 2011).

No que tange o II PNE, foi estabelecida a Meta 20 que definiu a aplicação percentual de recursos públicos na educação em relação ao PIB como forma de financiamento e ainda a ampliação progressivamente do investimento público na educação até atingir o patamar mínimo de 7\% do PIB (DOS SANTOS MACIEL, 2012). No estabelecimento do II PNE por meio da Emenda Constitucional $\mathrm{N}^{\circ} .59$ também ficou estipulado como deveria ser o percurso em relação ao aumento da porcentagem do PIB para se atingir os tão almejados $10 \%$ na educação. No entanto, pela dinâmica atual da economia do nosso País, a busca por esses $10 \%$ se mostra ainda distante de ser alcançado.

\section{GASTO MÉDIO POR ALUNO NA EDUCAÇÃO BRASILEIRA}

Ao se comparar a evolução dos gastos com a área da educação levando em conta o percentual do PIB de acordo com os dados do relatório anual publicado pela Organização para a Cooperação e Desenvolvimento Econômico (OCDE), observa-se que o Brasil teve um aumento expressivo nesses gastos entre 2000 e 2008 chegando a 5\% do PIB. Mesmo assim esses investimentos estão abaixo da média dos países que fazem parte da OCDE, que apresentaram um aporte na ordem de 6\% do PIB.

Mesmo com os avanços em relação aos recursos públicos destinados à educação, o que levou o Brasil a uma maior proximidade com a média dos valores observados nos Países membros da OCDE, se faz necessário pontuar que para se atingir os desafios propostos pelo II PNE, não é suficiente para o Brasil alcançar somente á média referente à dos países mais ricos, pois estes já apresentam um sistema educacional estruturado e consolidado. Os esforços para o Brasil se tornam muito mais complexos nesse sentido, tendo em vista que muitas escolas ain- 
da apresentam problemas estruturais, fazendo com que o nosso sistema educacional apresente muitas fragilidades.

Outro ponto relevante a ser comparado, diz respeito ao gasto público anual por estudante nos diferentes níveis da educação. A diferença em relação aos valores relacionados à educação infantil é vergonhosa, sendo que a média anual da OCDE é superior a US\$ 6.000 por aluno. No Brasil o gasto unitário não ultrapassa o valor de US\$2.000 ao ano, sendo este o menor valor encontrado dentre os países selecionados pela instituição (AMARAL, 2011).

Esse baixo valor por aluno na educação brasileira se repete nas outras etapas da educação como no ensino fundamental e médio, onde os gastos com alunos por ano ficam em torno dos mesmos US\$2.000, no entanto as médias da OCDE são ainda mais elevadas ficando em torno de US\$ 7.000 e próximo de US\$ 9.000 , respectivamente.

Somente na educação superior é que se observa um maior gasto por aluno no Brasil, em decorrência da inclusão dos custos com pesquisa, aposentadorias e hospitais universitários vinculados às Universidades Federais. Com isso, o valor unitário pode chegar em torno dos US $\$ 11.000$, fazendo com que esse valor fique mais próximo da média da OCDE, que é de quase US\$ 14.000 por estudante/ano. Entretanto, se apontados somente os valores que são investidos puramente no aluno, ou seja, as despesas correntes do ensino é possível que esse valor seja reduzido muitíssimo.

Conforme Amaral (2011), no que se refere ao aumento global dos gastos com educação, os valores anuais por aluno nas diferentes etapas da educação básica permanecem abaixo da média dos países que fazem parte da OCDE e ainda abaixo das médias dos países latino-americanos como Chile, Argentina e México.

No Brasil, o aporte de recursos públicos destinados para a área da educação encontra- se distante do que seria necessário para a redução dos desafios apresentados, sendo que os valores 
mínimos não apresentam mudanças significativas nem alteram o quadro de fragilidade social do país.

Após muita discussão, em dezembro de 2020, foi aprovado o novo Fundo de Manutenção e Desenvolvimento da Educação Básica e de Valorização dos Profissionais da Educação (FUNDEB). Por meio da Emenda Constitucional (EC) no 108/2020 o novo FUNDEB passou a ser um fundo permanente de apoio ao desenvolvimento da educação. Uma das maiores alterações é o aumento previsto por parte da complementação da União, que gradativamente deverá atingir o percentual de $23 \%$ dos recursos que irão compor o referido fundo em 2026. Esse escalonamento partirá dos 10\% previstos pela União; em 2021 esse valor atingirá 12\%; em 2022 serão 15\%; em 2023 serão 17\%; em 2024 serão 19\%; em 2025 serão 21\%; até que em 2026 atingirá os $23 \%$ preconizado.

Com essa porcentagem maior e com o novo sistema referente à distribuição, espera-se que mais municípios possam ser comtemplados e que se possam diminuir as desigualdades regionais e melhorar a educação em todo o País. Resta vigiar e acompanhar, na fase de execução orçamentária, para que fato isto se concretize sem qualquer alteração ou contingenciamento orçamentário.

De acordo com o Estudo Técnico (ET) n ${ }^{\circ}$ 24/2017, a cada quatro redes de ensino do País, uma apresentava valor menor que $\mathrm{R} \$ 3.600,00$ por aluno/ano, ou seja, $\mathrm{R} \$ 300,00$ por aluno/mês. É com esse Valor Aluno Ano Total (VAAT) que as diferentes Secretarias de Educação contam como recursos financeiros para garantir a remuneração dos servidores, manutenção predial das escolas, para custear a água, a energia e a internet, para investir na formação docente, na contratação de transporte escolar, na aquisição de material didático, ou seja, para a cobertura das despesas correntes da escola. Além de ser necessário um valor mínimo para o VAAT para que se consiga minimamente prover as escolas de recursos para o seu funcionamento, vale destacar que somente o aporte por aluno 
não pode ser tomado como solução para o referido problema, sendo o melhor uso para o referido recurso fator preponderante também, onde, a gestão aparece como algo fundamental para a otimização dos recursos existentes.

Os dados analisados pelo referido estudo revelam a existência de uma correlação forte entre a disponibilidade de recursos por aluno (VAAT) e os resultados do Índice de Desenvolvimento da Educação Básica (IDEB), ainda que o montante de recursos sozinho não determina o desempenho das redes de ensino.

De acordo com projeções da organização Todos Pela Educação (2019), o VAAT mínimo seria de $\mathrm{R} \$ 4.300$ pois, segundo pesquisa, mesmo aqueles municípios que demonstraram eficiência na alocação dos recursos financeiros, mostraram um baixo IDEB quando o VAAT foi inferior ao valor mínimo estipulado. A mesma organização apresentou que $46 \%$ das redes de ensino possuíam um VAAT abaixo de $\mathrm{R} \$ 4.300$, sendo fundamental um esforço nacional de financiamento para garantir que todas as localidades do país alcancem esse patamar mínimo de aporte de recursos do fundo público por aluno/ano. As simulações de impacto dessa proposta mostraram que a mudança do modelo redistributivo do FUNDEB é de suma importância para que as redes de ensino estaduais e municipais aproximem suas disponibilidades fiscais do VAAT em referência. Assim, o VAAT mínimo do país saltaria dos atuais $\mathrm{R} \$ 2.900$ para $\mathrm{R} \$$ 3.900, ainda abaixo do patamar apresentado de $\mathrm{R} \$ 4.300$, no entanto, com um valor mais próximo do preconizado pela referida organização.

Segundo Farenzena (2001), mesmo com a vinculação, o sistema enfrenta o risco pelo fato de ela estar intimamente associada à receita de tributos, sendo esse a maior fonte de recursos para a educação, condicionada às flutuações da economia e das políticas fiscais colocadas em prática pelos governantes. A falta de crescimento econômico do País, as autorizações de renúncias fiscais e os mecanismos que impedem a incidência 
dos percentuais mínimos na área da educação são situações que promovem sérios problemas em relação ao planejamento e consequentemente às execuções orçamentárias nessa área, em qualquer que seja o nível governamental (FARENZENA, 2001).

Ou seja, se na prática efetiva de execução orçamentária, não obtivermos os avanços acima descritos e defendidos pela sociedade brasileira em uníssono, continuaremos distantes do princípio constitucional que defende uma educação de qualidade, gratuita e para todos.

\section{TENDÊNCIAS E PERSPECTIVAS}

Como um todo, o orçamento do Ministério da Educação teve redução de 11,7\% entre 2014 e 2018: de $\mathrm{R} \$ 117,3$ bilhões para $\mathrm{R} \$ 103,5$ bilhões. O ensino superior, a educação básica e o ensino profissional sofreram maiores reduções. Na Tabela 1 são apresentadas as porcentagens referentes à redução dos investimentos em cada uma das áreas e os respectivos valores em bilhões.

Tabela 1: Redução dos investimentos na educação no período 2014-2018

\begin{tabular}{|l|c|r|c|}
\hline \multirow{2}{*}{ Fases do Ensino } & \multicolumn{2}{|l|}{$\begin{array}{l}\text { Redução dos } \\
\text { Investimentos } \\
\text { em \% }\end{array}$} & \multicolumn{2}{|c|}{ Valores em Bilhões } \\
\cline { 2 - 4 } & $-19,3 \%$ & $\mathbf{2 0 1 4}$ & $\mathbf{2 0 1 8}$ \\
\hline Educação Básica & $-27,6 \%$ & 36,2 & 29,3 \\
\hline Ensino Profissional & $-15,0 \%$ & 16,4 & 11,9 \\
\hline Ensino Superior & 39,2 & 33,4 \\
\hline
\end{tabular}

Fonte: Siafi (Sistema Integrado de Administração Financeira do Governo Federal). (Despesas primárias pagas no exercício, inclusive restos a pagar; valores corrigidos pelo Índice de Preços ao Consumidor Amplo).

Como é possível observar os valores relativos ao gasto em educação, já não eram suficientes para o desenvolvimento de uma educação de qualidade para todos. Com a redução desses valores, podemos afirmar que a educação irá se distanciar cada 
vez mais do que é preconizado pela CF de 1988, como uma educação de qualidade.

A questão se torna ainda mais complexa pelo fato de parte dos recursos da educação, serem destinados ao setor da previdência. Esses gastos são dependentes diretos das receitas destinadas a educação e não estamos aqui apontando a previdência como a causadora dos problemas relacionados à educação. De acordo com dados do SIAFI no período de 2014-2018 houve um aumento de 5,7\% nas despesas relacionadas à previdência social e o MEC isola esse montante de recursos, à parte do que é destinado à educação.

Assim, o documento final da CONAE (2010) apontava a necessidade de um aumento do aporte de recursos públicos para a educação. Contudo, as políticas do Governo Federal percorreram outra direção.

Conforme aponta De Souza Lima (2012), o Governo Federal com essas negativas em relação ao aumento do percentual do PIB estava e está muito mais preocupado com o pagamento dos juros e amortização da divida pública, pois em 2010 a União utilizou 44,93\% do orçamento geral para o pagamento dos juros e amortização da dívida pública e para a área da educação foi utilizado somente 2,89\% deste orçamento. De acordo com o Sistema Integrado de Planejamento e Orçamento (SIOP) do Governo Federal, em 2020 a União utilizou 39,08\% do orçamento geral para o pagamento dos juros e amortização da dívida pública e para a educação foi destinado somente $2,49 \%$ do referido orçamento.

Em relação ao II PNE o mesmo seguiu a mesma lógica do anterior, pois os valores alocados para a educação com base no percentual do PIB foram ínfimos quando comparado aos valores atribuídos para cada um dos alunos (DE SOUZA LIMA, 2012).

Os estudos referentes às políticas públicas de utilização somente do percentual do PIB como referência para justificar os valores deslocados para o financiamento da educação se tornam 
frágeis, pois, segundo Amaral (2011) a utilização somente dessa variável é um risco tendo em vista que se faz necessário verificar o valor do PIB do País; qual o percentual do referido PIB está sendo destinado para a educação e, por fim, qual a quantidade de alunos a serem atendidos pela rede de ensino (quantidade de pessoas do país que estão em idade educacional).

Em relação ao número de pessoas em idade educacional, Amaral (2011) aponta que os Países que apresentarem uma população em idade educacional superior a $30 \%$ da sua população total terão maiores desafios para a melhoria da qualidade da educação, pois, ainda segundo o autor, quanto menor for o número de pessoas em idade educacional, maiores serão os investimentos aplicados individualmente.

Como não é possível aumentar o PIB do País rapidamente e tampouco aumentar o percentual do PIB destinado à educação, o ideal é diminuir o número de pessoas em idade educacional, e isso a própria dinâmica populacional irá promover gradualmente, com base nas tendências demográficas atuais.

Desse modo, o Brasil não apresenta mecanismos para aumentar o valor do seu PIB. Não consegue aumentar o percentual do PIB a ser disponibilizado para a educação. O que lhe resta é aguardar que a própria dinâmica da sociedade promova uma redução no número de pessoas que estejam em idade educacional.

Com base nisso, Amaral (2016) apresenta uma projeção em que o Brasil somente irá atingir a marca de $30 \%$ da população total em idade educacional no ano de 2030, com essa marca o Brasil estará dentre os países que apresentam menores desafios relacionados à educação. Tal situação ocorrerá naturalmente, pela própria dinâmica populacional, o que irá contribuir para a redução dos problemas educacionais brasileiros.

O estabelecimento de um recurso mínimo de gastos com a educação por meio da vinculação constitucional propiciou a intenção de oferecer aportes crescentes de recursos para essa área (MELCHIOR, 1997). A retirada dessa vinculação coloca 
a educação à mercê das alterações políticas implementadas por seus dirigentes que poderão direcionar o orçamento a outras áreas que ao seu juízo possam melhor representar as suas concepções e projetos. Ou seja, derrubaria a intencionalidade de reversão do quadro inercial atual.

No que se refere à vinculação constitucional de recursos para a área da educação, essa é criticada pelo setor econômico do País; contudo, é fortemente defendida por aqueles que atuam em outras áreas.

Segundo a Proposta de Emenda Constitucional n ${ }^{\circ}$ 108/2020 de acordo com as projeções apresentadas pelo documento estipula que em 2026 o VAAT atingirá R\$ 5.508/aluno em 2.618 redes de ensino ( $47 \%$ das redes consideradas no cálculo). Todavia, não se pode deixar de pontuar que mesmo com esse maior aporte financeiro e com essa melhor forma de distribuição dos referidos recursos, a melhoria efetiva do sistema educacional demorará um tempo para ser observada tendo em vista a realidade das diferentes redes educacionais, pois existem redes que já apresentam uma estrutura adequada para o atendimento a esse aluno na qual o aumento do VAAT irá favorecer para que o aluno consiga ter um melhor desenvolvimento. Ainda assim, temos outras redes educacionais nas quais a estrutura é precária, como já pontuado, sendo parte ou até mesmo a totalidade desse maior aporte financeiro utilizado para essa adequação, como apontado pelo Censo da Educação Básica de 2019 em que somente 50,3\% das escolas públicas tem biblioteca ou sala de leitura e ainda que $37,2 \%$ das escolas públicas tem internet que possibilite seu uso no processo de ensino aprendizagem.

De acordo com Dweck, Rossi e Oliveira (2020) somente em 2019, a área da educação teve cortes orçamentários na ordem de $\mathrm{R}$ \$ 32,6 bilhões devido às políticas de austeridade. As políticas econômicas têm ditado os investimentos nas áreas sociais nos últimos anos. O MEC tem sido regido pelos limites das rubricas orçamentárias definidas pela pasta econômica e por propostas 
meramente burocráticas e voltadas à avaliação do sistema educacional, o que significa uma asfixia dos programas essenciais para o desenvolvimento do país no campo da educação.

Analisando o II PNE e a conjuntura atual do Brasil é possível afirmar que os problemas apresentados pela área da educação não foram alterados na última década, como preconizava a meta 20 do referido documento, a qual tratava em especial da ampliação do recurso público para a educação, de maneira progressiva até atingir 7\% do PIB em 2020. Na situação anterior a 2020, o Brasil já sinalizava grandes dificuldades em atingir a meta 20 do II PNE; no entanto, com a crise sanitária instalada com a pandemia da Covid-19, essa meta se colocou cada vez mais distante dos nossos horizontes.

Vale destacar que de acordo com os dados do Siafi (2020), o Ministério da Educação no referido ano gastou $\mathrm{R} \$ 48,2$ bilhões na educação básica. O valor é 10,2\% menor do que em 2019 e o menor desde 2010. O atual governo investiu no acumulado de 2019 e 2020, R \$ 7,2 bilhões o que representa $\mathrm{R} \$$ 6,3 bilhões a menos quando comparado com o mesmo período do governo anterior.

Em junho de 2020, ao completar seis anos de vigência, o Plano Nacional de Educação (PNE) apresentou um cenário de que $85 \%$ de seus dispositivos não tinham perspectiva de serem cumpridos até o final de sua vigência em 2024 (DWECK, ROSSI E OLIVEIRA, 2020).

Somente quatro das 20 metas apresentaram algum avanço, sendo que nenhuma foi totalmente cumprida. Diante dessa situação, o cenário atual é de preocupação com os preceitos preconizados pela CF de 1988 para a área da educação e as perspectivas para os próximos anos não se mostram animadoras, em especial com o cenário agravado pela pandemia da Covid-19. Registre-se que, no instante em que esse texto é escrito, o Brasil é o epicentro da pandemia estando em segundo lugar no ranking mundial em óbitos motivados pela pandemia. 


\section{CONSIDERAÇÕES POSSÍVEIS}

Desde os primórdios da educação no Brasil, um elemento político é constitutivo do dilema educacional brasileiro o acesso à educação. Essa realidade, entretanto, se caracterizou pela marca de um intocável privilégio social, cuja expansão começava e terminava nas fronteiras das camadas dominantes.

Ao longo de mais de quatro séculos, essa situação não foi superada sequer pelo processo instaurado com a Assembleia Nacional Constituinte, tendo em vista que a Constituição de 1988 manteve a distribuição dos percentuais referentes aos impostos, desconsiderando o aumento populacional e acima de tudo o aumento da população em idade educacional.

Além desses fatores a Constituição não assegurou a consolidação de um sistema público de ensino, deixando nas mãos dos governantes decisões cruciais sobre o investimento na educação.

A possível correlação que existe entre os recursos destinados para a educação e a melhoria da sua qualidade é o que estimula os diferentes movimentos sociais para continuarem com as suas lutas e reivindicações para a manutenção e ampliação dos recursos para a educação pública de qualidade e para todos, concretizando a Constituição Cidadã de 1988 no campo educacional.

Esperar somente que a dinâmica natural da sociedade promova a redução da população em idade educacional não é hipótese a ser considerada, pois nesse percurso quantos serão aqueles que não terão acesso a uma educação de qualidade.

Não obstante, em meio a esse cenário conturbado e de incertezas, administrar com competência e probidade os recursos já existentes no setor, é o mínimo que se espera de todas as esferas da administração pública entre os entes federativos.

\section{REFERÊNCIAS}

AMARAL, Nelson Cardoso. O novo PNE e o financiamento da educação no Brasil: os recursos como um percentual do PIB. III Seminário Brasileiro de Educação. CEDES, v. 28, 2011. Disponível em: http://files.adria- 
nonascimento.webnode.com.br/200000209- bba1cbc9ba/Amaral,\%20Nelson $\% 20$ Cardoso. $\% 20 \mathrm{O} \% 20 \mathrm{PNE} \% 20 \mathrm{e} \% 20 \mathrm{o} \% 20$ Financimaneto $\% 20 \mathrm{da} \% 20$ Educa $\%$ C3\%A7\%C3\%A3o\%20no\%20Brasil.pdf Acesso em: 10 mar. 2020.

AMARAL, Nelson Cardoso A educação superior brasileira: dilemas, desafios e comparações com os países da OCDE e do BRICS. Revista Brasileira de Educação, v. 21, no 66, p. 717- 736, 2016. Disponível em: http://www. redalyc.org/articulo.oa?id=27546753010 Acesso em: 01 jun. 2021.

BRASIL. Constituição da República dos Estados Unidos do Brasil, de 16 de julho de 1934. Disponível em: http://www.planalto.gov.br/ccivil_03/ constituicao/constituicao34.htm Acesso em: 10 mar. 2020.

BRASIL. Constituição dos Estados Unidos do Brasil, de 10 de novembro de 1937. Disponível em: http://www.planalto.gov.br/ccivil_03/Constituicao/Constituicao37.htm Acesso em: 10 mar. 2021.

BRASIL. Constituição dos Estados Unidos do Brasil, de 18 de setembro de 1946. Disponível em: http://www.planalto.gov.br/ccivil_03/constituicao/ constituicao46.htm Acesso em: 10 mar. 2020.

BRASIL, Lei $\mathbf{n}^{\mathbf{0}}$ 4.024, de 20 de dezembro de 1961. Fixa as Diretrizes e Bases da Educação Nacional. Diário Oficial daUnião, 1961. Disponível em: http://www.planalto.gov.br/ccivil_03/LEIS/L4024.htm Acesso em: 15 mar. 2020.

BRASIL. Constituição da República Federativa do Brasil, de 24 de janeiro de 1967. Disponível em: http://www.planalto.gov.br/ccivil_03/constituicao/constituicao67.htm Acesso em: 15 mar. 2020.

BRASIL. Lei $\mathbf{n}^{\mathbf{0}}$ 5.692, de 11 de agosto de 1971. Fixa diretrizes e bases para o ensino de $1^{\circ}$ e $2^{\circ}$ graus, e dá outras providências. Diário Oficial da União, 1971. Disponível em: https://www2.camara.leg.br/legin/fed/lei/1970-1979/ lei-5692-11-agosto-1971-357752-norma- pl.html Acesso em: 20 mar. 2020.

BRASIL. Constituição da República Federativa do Brasil. Brasília-DF, 1988. Disponível em: http://www.planalto.gov.br/ccivil_03/constituicao/ constituicaocompilado.htm Aceso em 30 mar. 2020.

BRASIL. Lei $\mathbf{n}^{\circ} \mathbf{9 . 3 9 4}$, de 20 de dezembro de 1996. Estabelece as diretrizes e bases da educação nacional. Diário Oficial da União, v. 134, n. 248, 
1996. Disponível em: http://www.planalto.gov.br/ccivil_03/leis/19394.htm Aceso em: 25 mar. 2020.

BRASIL. Emenda Constitucional no. 59, de 11 de novembro de 2009. Diário Oficial da União. Brasília-DF, 13 nov. 2009. Disponível em: http:// www.planalto.gov.br/ccivil_03/constituicao/emendas/emc/emc59.htm Acesso em: 10 mar. 2020.

BRASIL. CONAE-2010 - Construindo o sistema nacional articulado de educação: o plano nacional de educação, diretrizes e estratégias de ação. (Documento Final). Brasília: MEC, 2010. Disponível em: http://pne.mec. gov.br/images/pdf/CONAE2010_doc_final.pdf Acesso em: 10 mar. 2020.

BRASIL, Estudo Técnico 24/2017 - Universalização, qualidade e equidade na alocação de recursos do Fundo de Manutenção e Desenvolvimento da Educação Básica e de Valorização dos Profissionais da Educação (FUNDEB). Câmara dos Deputados, Brasília, 2017. Disponível em: https:// www2.camara.leg.br/orcamento-da-uniao/estudos/2017/et-24-2017-universqualidade-equidade-fundeb Acesso em: 21 mai. 2021.

BRASIL. Emenda Constitucional $\mathbf{n}^{\mathbf{0}} \mathbf{1 0 8} / 2020$. Estabelece critérios de distribuição da cota municipal do Imposto sobre Operações Relativas à Circulação de Mercadorias e sobre Prestações de Serviços de Transporte Interestadual e Intermunicipal e de Comunicação (ICMS) e para dispor sobre o FUNDEB. Congresso Nacional. Brasília, 2020. Disponível em: https:/ / www.in.gov.br/en/web/dou/-/emenda-constitucional-n-108-274384345 Acesso em: 21 mai. 2021.

COSTA, Messias. A educação nas constituições do Brasil: dados e direções. Dp\&A Editora, 2002.

CURY, Carlos Roberto Jamil. A educação e a primeira Constituinte Republicana. In: FÁVERO, Osmar (org.). A educação nas Constituintes Brasileiras 1823-1988. 2. ed. Campinas, SP; Autores Associados, 2001.

DE REZENDE PINTO, José Marcelino. Os recursos para a educação no Brasil no contexto das finanças públicas. Editora Plano, 2000.

DE SOUZA LIMA, Kátia Regina. A educação superior no plano nacional de educação 2011- 2020. Perspectiva, v. 30, n. 2, p. 625-256, 2012. Disponível em: https://periodicos.ufsc.br/index.php/perspectiva/article/ view/2175-795X.2012v30n2p625 Acesso em: 20 abr. 2020. 
DOS SANTOS MACIEL, Willians Kaizer. Metodologia para o cálculo do indicador do Investimento Público em Educação em relação ao PIB de 2000 a 2010. Textos para discussão, n. 34, p. 30-30, 2012. Disponível em: http://rbep.inep.gov.br/ojs3/index.php/td/article/view/3862 Acesso em 25 abr. 2020.

DWECK, Esther; ROSSI, Pedro e OLIVEIRA, Ana Luiza Matos de. Economia pós- pandemia: desmontando os mitos de austeridade fiscal e construindo um novo paradigma econômico. Autonomia Literária, São Paulo, 2020.

FARENZENA, Nalú. Diretrizes da política de financiamento da educação básica brasileira: continuidades e inflexões no ordenamento constitucional-legal: 1987-1996. 2001. Tese de Doutorado. Universidade Federal do Rio Grande do Sul. Disponível em: http://repositorio.minedu. gob.pe/handle/20.500.12799/24 Acesso em: 10 mai. 2020.

HORTA, José Silvério Baía. A educação no Congresso Constituinte de 1966-67. In: FÁVERO, Osmar (org.). A educação nas Constituintes brasileiras 1823-1988. 2.ed. Campinas, SP; Autores associados, 2001.

MELCHIOR, José Carlos de Araújo. Mudanças no financiamento da educação no Brasil. Campinas- SP: Autores Associados, 1997.

ROCHA, Marlos Bessa Mendes. Tradição e modernidade na educação: o processo constituinte de 1933-34. In: FÁVERO, Osmar (org.). A educação nas Constituintes brasileiras 1823-1988. 2. ed. Campinas, SP; Autores Associados, 2001. p. 119-138.

TODOS PELA EDUCAÇÃO. Nota Técnica: análise da relação entre investimento por aluno e qualidade do ensino. 2019. Disponível em: https:// www.todospelaeducacao.org.br/_uploads/_posts/319.pdf?477736800 Acesso em: 21 mai. 2021. 